\title{
Multiple Exostosis and Embryonic Clubfoot in a Premature Newborn: Case Report
}

Fernanda Martins Coelho Catharino ${ }^{1}$, Marco Orsini ${ }^{2 *}$, Jacqueline Stephanie Fernandes do Nascimento ${ }^{3}$, Antonio Marcos da Silva Catharino ${ }^{4}$ and Marco Azizi ${ }^{5}$

${ }^{1}$ Post-Graduated in Pediatrics PUC-RJ, Brazil

${ }^{2}$ Iguaçu University (UNIG), Severino Sombra University (USS), Brazil

${ }^{3}$ Iguaçu University (UNIG) - Faculty of Medicine, Brazil

${ }^{4}$ Master in Neurology-UNIRIO; Titular Member of the Brazilian Academy of Neurology; Associated Professor of Neurology - UNIG; Physician at the Neurology Service of the General Hospital of Nova Iguaçu, Brazil

${ }^{5}$ Unig University, Brazil

*Corresponding author: Antonio Marcos da Silva Catharino - Rua Gavião Peixoto

70, Sala 811 - Icaraí - Niterói - Rio de Janeiro - Brasil - CEP: 24230-100, Brazil.
Received Date: July 23, 2020

Published Date: August 24, 2020

\section{Introduction}

Multiple exostosis is an inherited, autosomal dominant condition, characterized by multiple cartilaginous lesions,

developed from the metaphysis of long bones, mainly in the proximal and distal regions of the femur [1].

Case Report

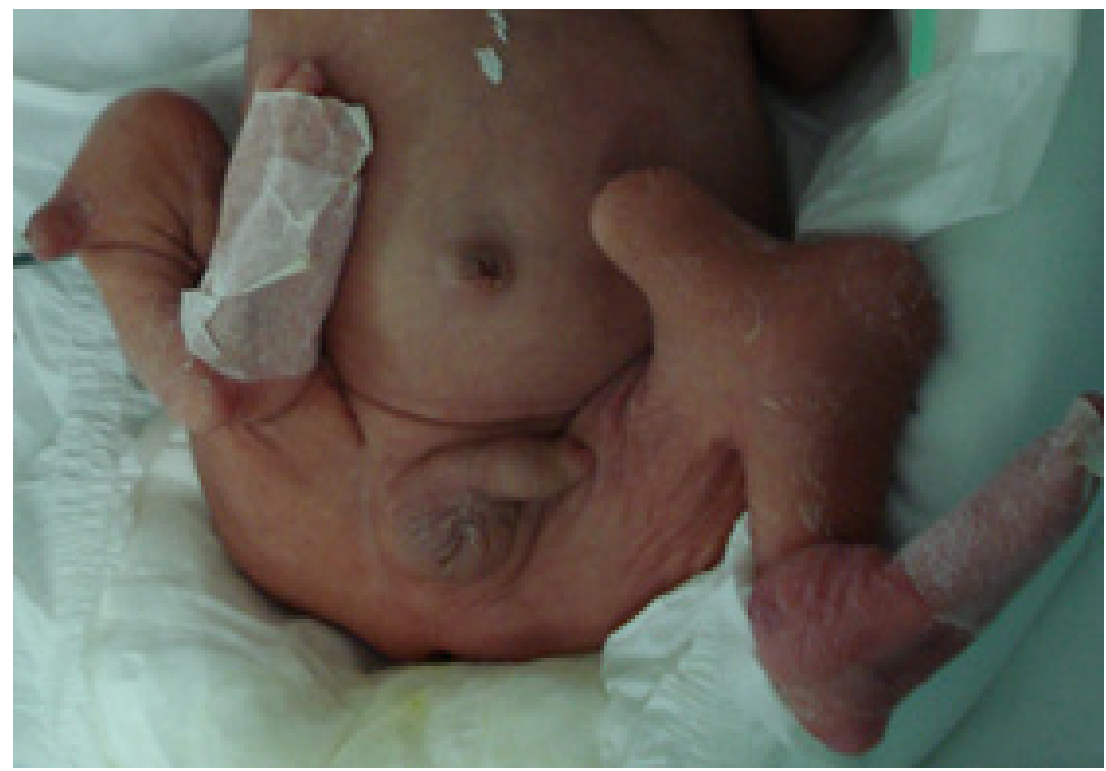

Figure 1: Exostosis in lower limbs and embryonic clubfoot. 


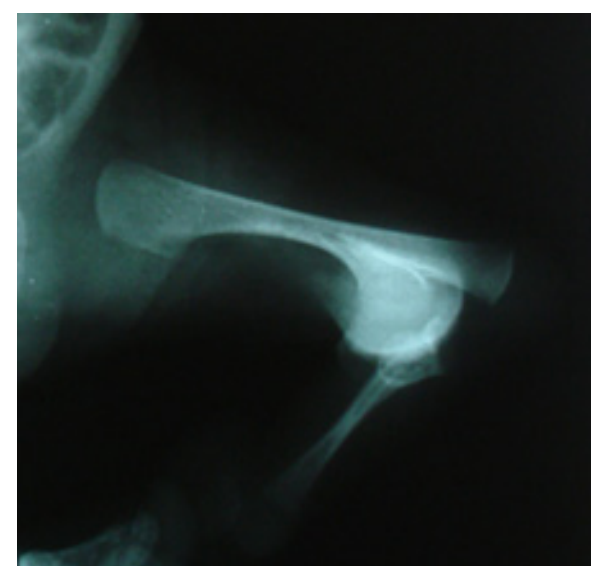

Figure 2: Exostosis in lower limbs and embryonic clubfoot.

Premature, male newborn, 27 weeks of gestational age, birth weight $1215 \mathrm{~kg}$, Apgar score in the first, fifth and tenth minutes was, respectively, 2/6/8, vaginal delivery, blood group A. He had structural abnormalities in lower limbs compatible with multiple exostosis and embryonic clubfoot (Figure 1), evidenced by simple radiography (Figure 2). Mother without prenatal care, with membranes' rupture for over a month, Gestation I / Delivery 0, HIV / VDRL / Coombs direct negative, blood group A [2].

\section{Discussion}

The exostosis can be asymptomatic or associated with complications caused by compression of adjacent structures [3]. The diagnosis is made in the first life decade, based on clinical evaluation and radiological exams, changes are rarely present at birth $[1,2]$.

\section{Conclusion}

Multiple exostosis is not classified as a true neoplasm, however, it is configured by the appearance, in childhood and adolescence, of bony protuberances surrounded by hyaline cartilage. The primary involvement occurs in the tubular bones, iliac wing and scapula, however, the entire skeleton can be compromised. It is known that less than $5 \%$ of cases evolve to the malignant form: chondrosarcoma. Congenital clubfoot, in turn, is characterized by generalized deformations of the musculoskeletal tissues distal to the knee. Until the current date, there are no reports of a causal relationship for both injuries, and further studies on this relationship are necessary.

\section{Acknowledgement}

None.

\section{Conflict of Interest}

No conflict of interest.

\section{References}

1. Legeai-Malett, L (2002) Hereditary Multiple Exostosis. Disponível em: www.orpha.net/data/patho/GB/uk-HME.pdf.

2. Canet AR, Cuixart VB, Silveria LL (2006) Exostosis múltiple. An Pediatr (Barc) 65(5): 500-510.

3. Lemos MC, Peter Kotanko, Paul T Christie, Brian Harding, Theodora Javor, et al. (2005) A Novel EXT1 Splice Site Mutation in a Kindred with. J Clin Endocrinol Metab 90(9): 5386-5392. 